\title{
Comparison of a loop-mediated isothermal amplification for orf virus with quantitative real-time PCR
}

\author{
Guangxiang Wang ${ }^{1,4}$, Youjun Shang ${ }^{3,4}$, Yanhua Wang ${ }^{1,4}$, Hong Tian $^{2}$ and Xiangtao Liu ${ }^{1,4^{*}}$
}

\begin{abstract}
Background: Orf virus (ORFV) causes orf (also known as contagious ecthyma or contagious papular dermatitis), a severe infectious skin disease in goats, sheep and other ruminants. Therefore, a rapid, highly specific and accurate method for the diagnosis of ORFV infections is essential to ensure that the appropriate treatments are administered and to reduce economic losses.

Methods: A loop-mediated isothermal amplification (LAMP) assay based on the identification of the F1L gene was developed for the specific detection of ORFV infections. The sensitivity and specificity of the LAMP assay were evaluated, and the effectiveness of this method was compared with that of real-time PCR.

Results: The sensitivity of this assay was determined to be 10 copies of a standard plasmid. Furthermore, no crossreactivity was found with either capripox virus or FMDV. The LAMP and real-time PCR assays were both able to detect intracutaneous- and cohabitation-infection samples, with a concordance of 97.83\%. LAMP demonstrated a sensitivity of $89.13 \%$.

Conclusion: The LAMP assay is a highly efficient and practical method for detecting ORFV infection. This LAMP method shows great potential for monitoring the prevalence of orf, and it could prove to be a powerful supplemental tool for current diagnostic methods.
\end{abstract}

Keywords: Orf virus, Loop-mediated isothermal amplification (LAMP), Real-time PCR

\section{Background}

The orf virus (ORFV) is the prototype member of the Parapoxvirus genus within the Poxviridae family. The ORFV has a worldwide distribution and causes an infectious skin disease known as contagious ecthyma in goats, sheep and other ruminants [1]. For susceptible young sheep in an epidemic situation, mortality can reach $90 \%$ [2]. Therefore, a practical and reliable method for the diagnosis of ORFV infections is required.

For diagnosis of such infections, clinical signs, virus isolation and electron microscopy are commonly used along with serological tests. However, these methods are

\footnotetext{
* Correspondence: hnxiangtao@163.com

'State Key Laboratory of Veterinary Etiological Biology, Lanzhou 730046, China

${ }^{4}$ Lanzhou Veterinary Research Institute, Chinese Academy of Agriculture Science, Lanzhou 730046, China

Full list of author information is available at the end of the article
}

laborious, time-consuming and, in some cases, not effective. For example, virus isolation can be unsuccessful at times, even when virus-like particles are observed in the lesions resulting from infection. Goats and sheep are commonly infected with the virus, yet serological tests have not confirmed the cause of clinical signs. PCRbased diagnostic assays have been developed for the sensitive and specific detection of ORFV infections [3-7]. However, these assays have not been widely adopted in resource-poor regions due to their relatively complex nature, as well as the need for both expensive equipment and highly trained personnel $[8,9]$.

Loop-mediated isothermal amplification (LAMP) is a simple technique that rapidly amplifies specific DNA sequences with high sensitivity under isothermal conditions [10]. LAMP products can easily be detected by the naked eye due to the formation of magnesium pyrophosphate, a turbid white by-product of DNA amplification

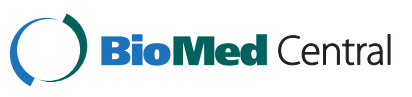


that accumulates as the reaction progresses [11]. In addition, LAMP products can be detected by direct fluorescence [12]. Other fluorescent dyes, such as ethidium bromide, SYBR green and Evagreen, have also been used for visualization of LAMP products [13]. Furthermore, Thekisoe et al. have reported that LAMP reagents are relatively stable even when stored at 25 or $37^{\circ}$ $\mathrm{C}$, which supports the use of LAMP in field conditions and resource-poor laboratories [14]. Recently, LAMP assays targeting the B2L and DNA polymerase genes of ORFV have been developed, and these methods were found to be powerful diagnostic tools $[8,9]$.

The F1L gene is part of the highly conserved central region of the ORFV genome [15,16]. In the present study, a LAMP assay was developed to specifically identify the F1L gene sequence to facilitate the detection of ORFV infections and the effectiveness of this method was compared with that of real-time PCR.

\section{Results}

\section{Detection of LAMP product}

The LAMP products were electrophoresed on a $1.5 \%$ agarose gel stained with ethidium bromide solution and visualized under UV light. In addition, visual inspection of the LAMP products was performed by adding SYBR Green I to the reaction mixture tube and observing the fluorescent signals of the solutions under daylight conditions against a black background (Figure 1).

\section{Sensitivity of LAMP}

To determine the detection limit of the LAMP assay, 10-fold serial dilutions of the PF1L were amplified using LAMP. As determined using both 1.5\% agarose gel electrophoresis and color inspection with SYBR Green I dye, the detection limit of the LAMP assay was determined to be 10 copies of DNA (Figure 2).

\section{Specificity of LAMP}

The specificity of the LAMP assay was evaluated using the genomic DNA of 10 known ORFV isolates, capripox virus and FMDV. Only the specific ORFV target DNA was amplified by LAMP. No cross-reactivity was observed with the DNA samples of capripox virus or FMDV. These results confirm that the LAMP assay is highly specific (Figure 3).

\section{Sensitivity and specificity of real-time PCR}

To determine the detection limit of the real-time PCR, the copy number of a recombinant plasmid containing the B2L gene (PB2L), which was previously constructed by our lab, was calculated as described below. PB2L was amplified from 10-fold serial dilutions using real-time PCR. The detection limit was found to be 10 copies/ $\mu$ l.

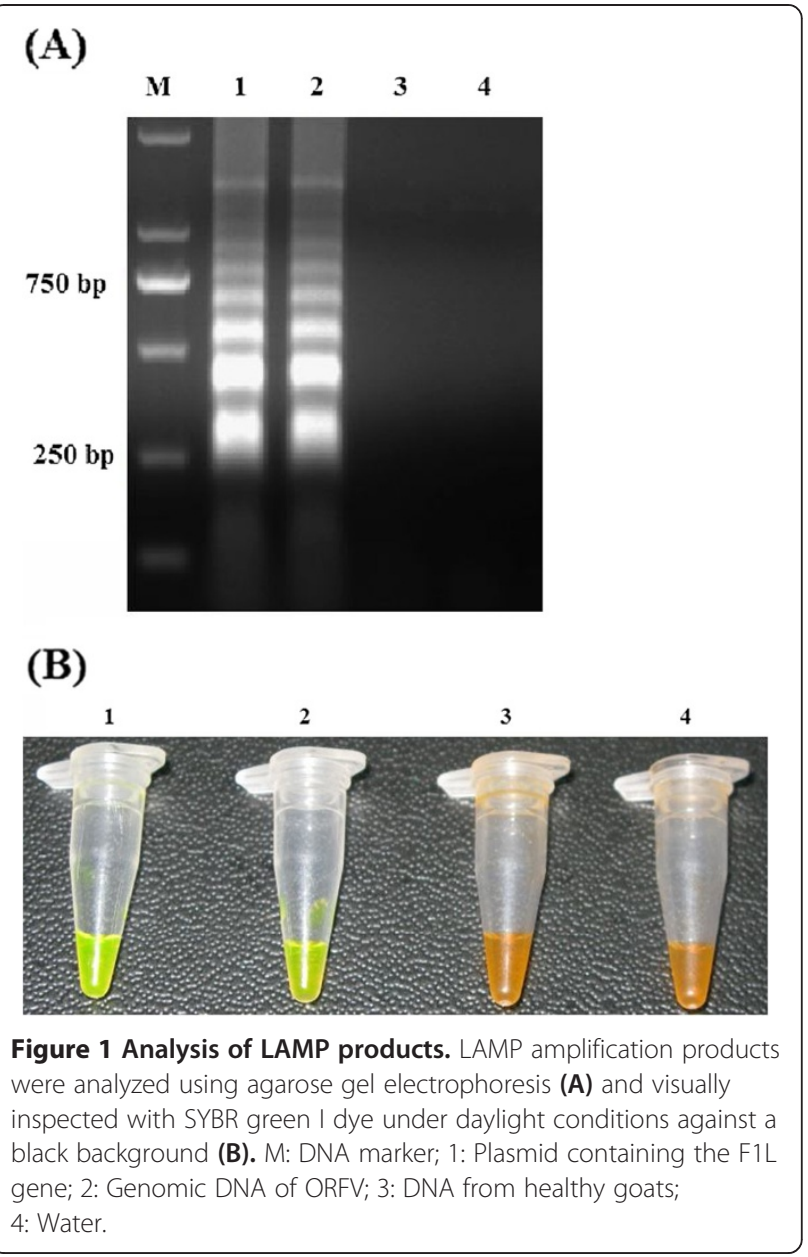

The real-time PCR slope was -3.218 , with an $\mathrm{R}^{2}=1$ and a reaction efficiency of $104.5 \%$. Moreover, the standard curve generated using the 10-fold serial dilutions of the plasmid was linear over eight orders of magnitude ( 1 to $10^{8}$ copies/ $\left.\mu \mathrm{l}\right)$, demonstrating that real-time PCR can be used to accurately quantify this target DNA over a large range of concentrations (Figure 4A).

The primers chosen for real-time PCR were initially validated by monitoring product amplification with SYBR Green I. Melting curve analysis showed a unique peak at $86^{\circ} \mathrm{C}$, indicating the formation of a single PCR product without the presence of nonspecific amplification products or primer dimers (Figure 4B). To further determine the specificity of the amplification reaction with the chosen primers, the SYBR Green I-based realtime PCR was performed using DNA from 10 different isolates of ORFV, capripox virus and FMDV. All ORFV DNA samples tested using SYBR Green I-based realtime PCR yielded a positive result. However, the DNA samples from capripox virus and FMDV did not yield an amplification signals (Figure 4C). 


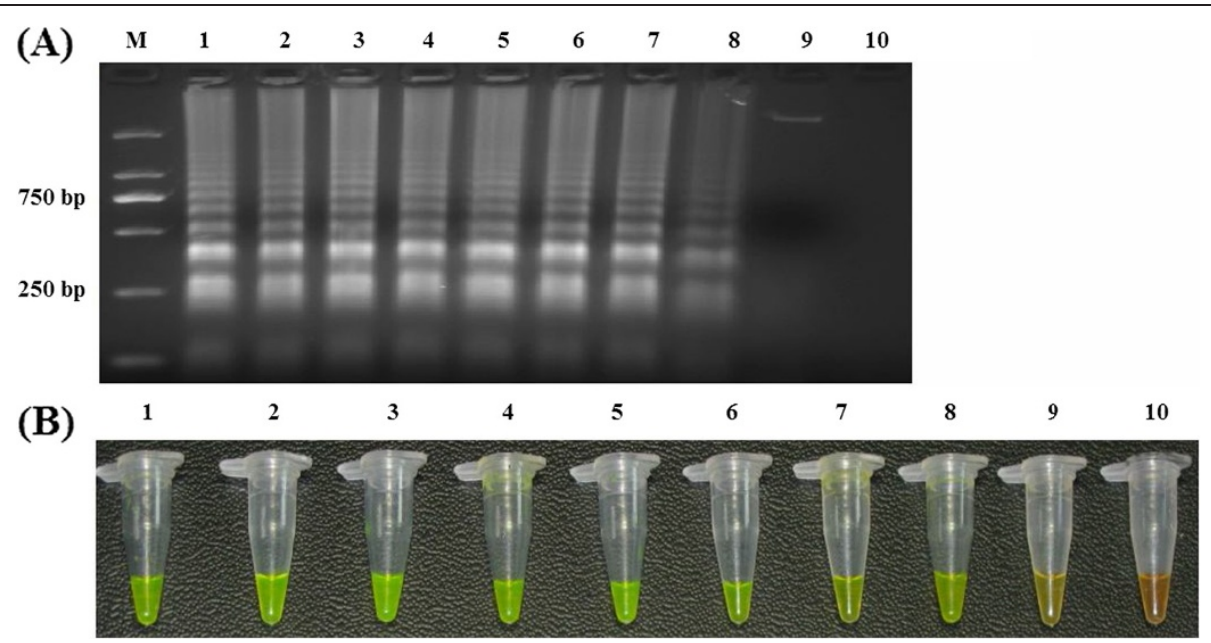

Figure 2 Sensitivity of LAMP. Agarose gel electrophoresis (A) and visual inspection using SYBR Green I staining of the LAMP products (B). M: DNA marker; $1-9$ are the reaction results from a 10 -fold serial dilution of plasmid containing the $\mathrm{F} 1 \mathrm{~L}$ gene from $10^{8}$ to $10^{\circ}$ copies per reaction; 10 : Negative control.

\section{Evaluation of the LAMP assay using samples from} experimentally infected goats

To evaluate the practicality and efficiency of the LAMP assay, its ability to detect ORFV infections was tested using the skin lesions from experimentally infected goats. Forty-six samples of skin lesions from four experimentally infected goats were tested using the LAMP (by both visual inspection and agarose gel electrophoresis methods) and real-time PCR assays. Forty-one samples were determined to be positive by both LAMP and realtime PCR. One sample was determined to be negative by LAMP assay but positive by real-time PCR. The sensitivities of the LAMP and real-time PCR assays were $89.13 \%$ and $91.30 \%$, respectively (Table 1 ), and the results were very similar between the two assays.

\section{Discussion}

Orf is distributed throughout many countries [2,17-23], and ORFV infections can cause weight loss and poor development as the disease prevents host animals from feeding. Therefore, the development of a rapid, simple and sensitive detection method for ORFV infections is required. For the diagnosis of ORFV infections, the LAMP assay has many advantages, such as simplicity, rapidity and inexpensiveness, compared with other nucleic acid-based tests $[8,9]$. In addition, previous reports have demonstrated that the sensitivity of the LAMP is higher than that of conventional PCR or nested PCR for detecting ORFV infections [8,9]. Therefore, this method shows great potential for use in resource-limited veterinary laboratories in developing countries (e.g., China),

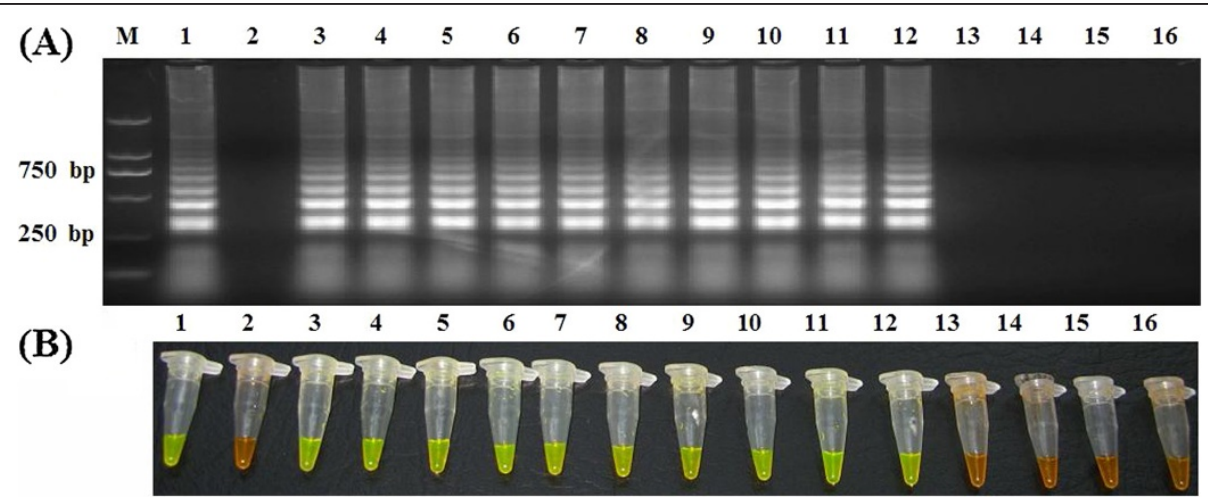

Figure 3 Specificity of LAMP. Agarose gel electrophoresis (A) and visual inspection using SYBR Green I staining (B). M: DNA marker; 1: Plasmid containing the F1L gene; 2: Negative control; 3-12: ORFV/HB/CHA, ORFV/Naccine/CHA, ORFV/Xinjiang/CHA, ORFV/Chongqing/CHA, ORFV/Shanxi/ CHA, ORFV/Guangxi/CHA, ORFV/Gansu/CHA, ORFV/Liaoning/CHA, ORFV/Jilin/CHA and ORFV/Sichuan/CHA; 13 and 14: FMDV/O/CHA and FMDV/ Asia I/JS; 15 and 16: Capripox virus/China Vaccine and Capripox virus/Henan/CHA. 
(A)

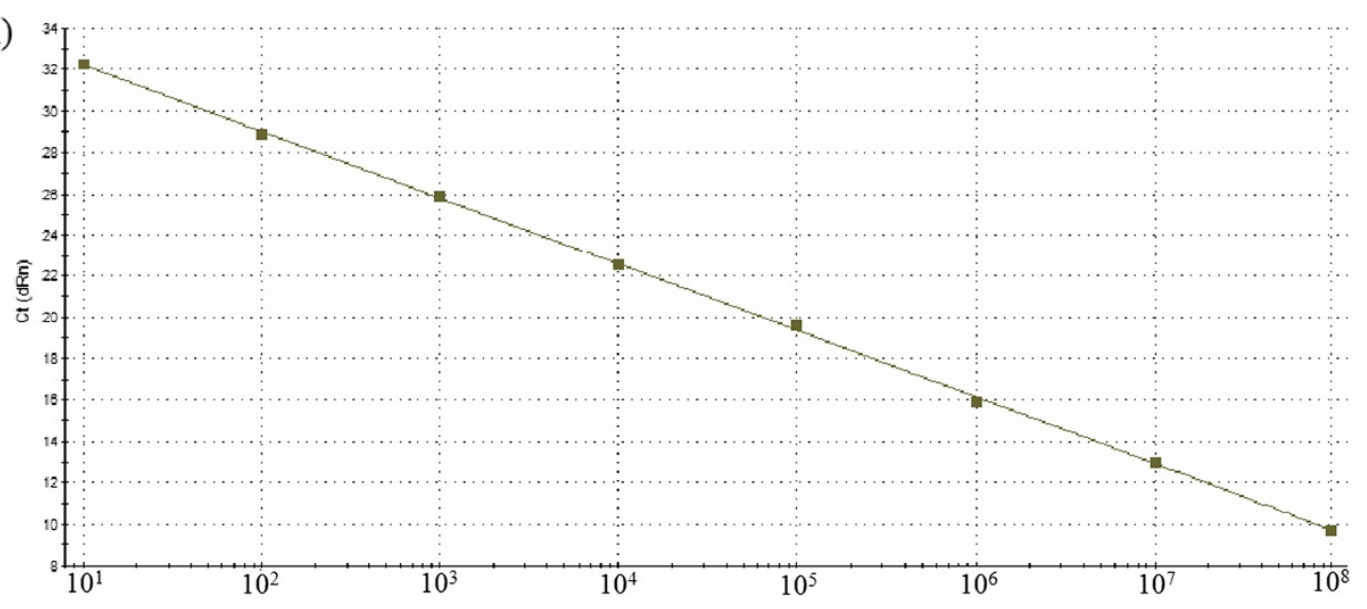

(B)

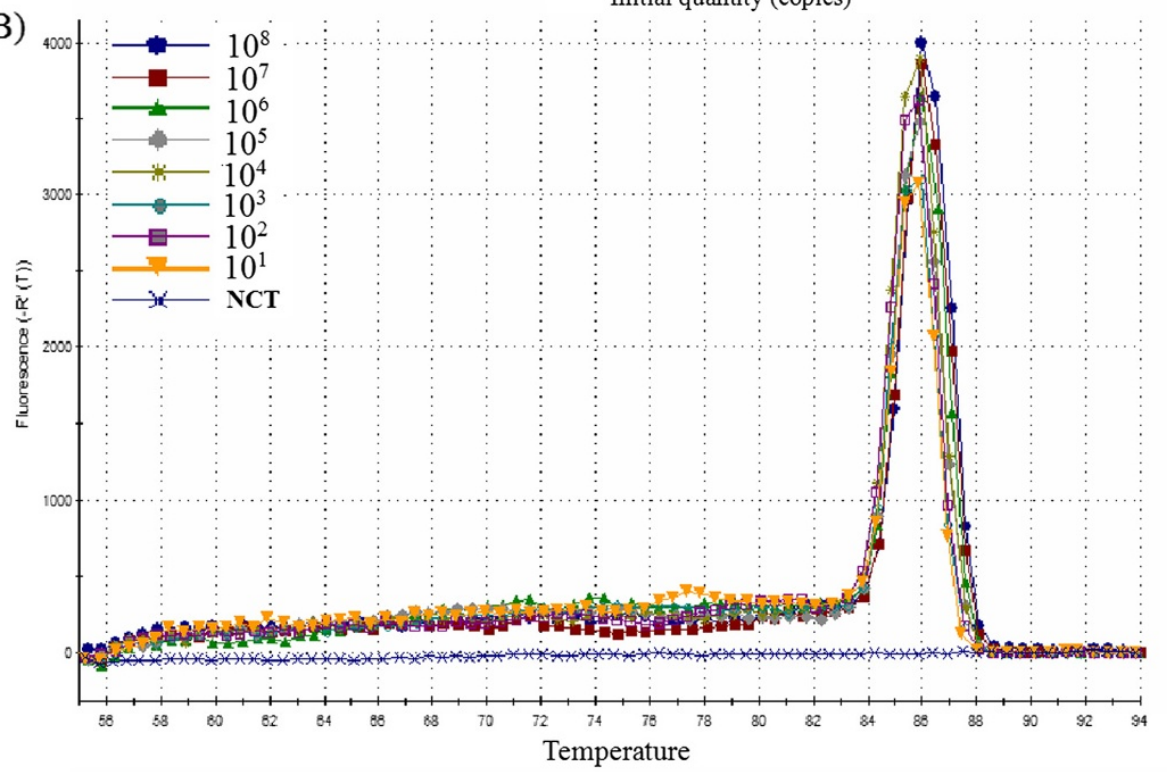

(C)

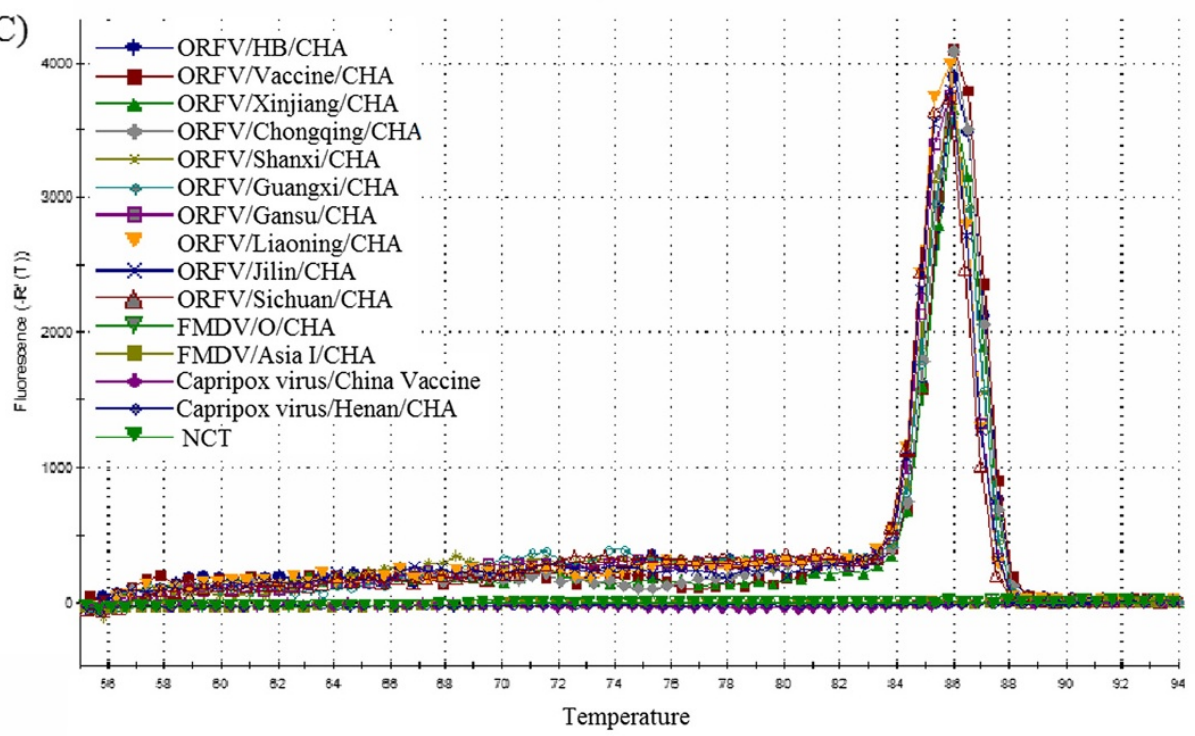

Figure 4 (See legend on next page.) 
where many endemic diseases exist. In the present study, we evaluated the sensitivity and specificity of the rapid diagnostic LAMP method.

The simplest way of detecting LAMP products is to visually inspect the white turbidity that results from magnesium pyrophosphate accumulation as a by-product of the reaction [11]. However, a small amount of this white precipitate is not always distinguishable from other white precipitates, such as proteins or carbohydrates that can be derived from the templates. Therefore, existing "fieldfriendly" LAMP-based detection systems are still imperfect. Previous report has demonstrated that amplified DNA can be stained (using PicoGreen or ethidium bromide) and visualized in solution with the same sensitivity as agarose gel electrophoresis [8]. In this study, we used the dye SYBR Green I to detect the amplified DNA products. Positive and negative reactions could be differentiated by distinctly different colors when viewed under daylight conditions against a black background (Figure 1). Consistent with previous report, this color inspection method was found to have the same detection limit as agarose gel electrophoresis (Figure 2), which should facilitate the rapid screening of samples without the need for gel electrophoresis. These results indicate that visual color inspection of LAMP products using the SYBR Green I dye should be practical under field conditions.

The reliability of a LAMP assay depends largely on the specificity of the primer sets being used. These primer sets in this study-two outer primers (F3 and B3) and two inner primers (FIP and BIP)-allow for the recognition of six sites in the target sequence that are specific to the F1L gene and that are necessary for the LAMP reaction to occur. Based on the sequences of the ORFV F1L gene available in GenBank and the sequences of ORFV isolates from China, we designed and tested several sets of primers using comparative experiments, and the primer sets that yielded the highest specificity and sensitivity in the LAMP assay is reported here. Our LAMP assay showed high specificity and sensitivity, as it yielded positive results for all 10 of the known ORFV isolates but did not amplify the negative control samples (Figure 3).

Samples from experimentally infected goats were tested using both the LAMP and real-time PCR assays. The LAMP assay correctly identified 41 out of 46 samples as positive (89.13\%), and the real-time PCR assay correctly identified 42 out of 46 samples as positive (91.30\%). ORFV DNA could be detected in most of the intracutaneous- and cohabitation-infection samples from the time of lesion presentation to recovery (Table 1). Therefore, we observed a very good agreement between the LAMP and real-time PCR results. Only one sample was identified as negative by LAMP (both by visual inspection and agarose gel electrophoresis) but as positive by real-time PCR. This discrepancy was most likely due to very low ORFV levels in this sample, which may have been beyond the detection limit of LAMP. This result suggests that the sensitivity of LAMP is slightly lower than that of real-time PCR. However, it is important to consider that real-time PCR is a time-consuming procedure that requires expensive and relatively complicated equipment, including a thermal cycler with real-time monitoring and data-analysis systems. Therefore, this LAMP-based assay has clear advantages over real-time PCR in terms of practicality, and it can be easily used in any standard diagnostic laboratory, particularly in developing countries where the disease is prevalent.

\section{Conclusions}

We show that a LAMP assay based on amplification of the ORFV F1L gene is rapid, highly specific and accurate for the detection of ORFV infections. The sensitivity of this LAMP $(89.13 \%)$ was higher than previously reported (70\% and $74.3 \%$, respectively). Furthermore, this color inspection method with SYBR Green I dye had the same sensitivity as agarose gel electrophoresis, which should facilitate the rapid large-scale screening of samples and the rapid diagnosis of ORFV infections under field conditions without the use of agarose gel electrophoresis. Therefore, we conclude that this LAMP is a practical and reliable method for detecting ORFV infections, and we suggest that this test can be adopted as a powerful supplemental tool to current diagnostic assays.

\section{Materials and methods}

\section{Intracutaneous and cohabitation infection of goats}

Four healthy 12- to 14-week-old goats were selected for this study. The ORFV strain ORFV/HB/09 [22] was propagated in bovine testicular cells using Eagle's minimal essential medium (Shanghai Gaochuang Medical Science And Technology Co., Ltd, Shanghai, China) containing $10 \%$ fetal calf serum $\left(\mathrm{TCID}_{50}=10^{-5.3} / 0.1 \mathrm{ml}\right)$, which was used to infect the goats to prepare the ORFV-positive samples. Two goats were inoculated intradermally on oral mucosa with viral supernatant $(0.2 \mathrm{ml}$ per goat $)$ and housed individually. After 7 days, each non-inoculated goat was housed with one inoculated goat, thereby making two replicate cohabitation groups. The clinical signs and 
Table 1 Comparison of LAMP and real-time PCR for detection of orf from intracutaneous and cohabitation infections

\begin{tabular}{|c|c|c|c|c|}
\hline \multirow{2}{*}{$\begin{array}{l}\text { The route of } \\
\text { infection }\end{array}$} & \multirow[t]{2}{*}{ Samples } & \multirow{2}{*}{$\begin{array}{l}\text { Days } \\
\text { after } \\
\text { infection }\end{array}$} & \multicolumn{2}{|l|}{ Assay } \\
\hline & & & LAMP & real-time PCR \\
\hline \multirow[t]{26}{*}{ Intracutaneous } & \multirow[t]{13}{*}{ Goat 1} & 10 & + & + \\
\hline & & 11 & + & + \\
\hline & & 12 & + & + \\
\hline & & 13 & + & + \\
\hline & & 14 & + & + \\
\hline & & 15 & + & + \\
\hline & & 16 & + & + \\
\hline & & 17 & + & + \\
\hline & & 18 & + & + \\
\hline & & 20 & + & + \\
\hline & & 22 & + & + \\
\hline & & 25 & - & - \\
\hline & & 28 & + & + \\
\hline & \multirow[t]{13}{*}{ Goat 2} & 12 & + & + \\
\hline & & 13 & + & + \\
\hline & & 14 & + & + \\
\hline & & 15 & + & + \\
\hline & & 16 & + & + \\
\hline & & 17 & + & + \\
\hline & & 18 & + & + \\
\hline & & 19 & + & + \\
\hline & & 20 & + & + \\
\hline & & 23 & + & + \\
\hline & & 25 & + & + \\
\hline & & 27 & + & + \\
\hline & & 30 & - & + \\
\hline \multirow[t]{15}{*}{ Cohabitation } & \multirow[t]{9}{*}{ Goat 3} & 18 & + & + \\
\hline & & 21 & + & + \\
\hline & & 22 & + & + \\
\hline & & 23 & + & + \\
\hline & & 24 & + & + \\
\hline & & 25 & + & + \\
\hline & & 26 & + & + \\
\hline & & 27 & - & - \\
\hline & & 29 & + & + \\
\hline & \multirow[t]{6}{*}{ Goat 4} & 17 & + & + \\
\hline & & 19 & + & + \\
\hline & & 20 & + & + \\
\hline & & 21 & + & + \\
\hline & & 22 & + & + \\
\hline & & 23 & + & + \\
\hline
\end{tabular}

Table 1 Comparison of LAMP and real-time PCR for detection of orf from intracutaneous and cohabitation infections (Continued)

\begin{tabular}{llll}
\hline 24 & + & + \\
25 & + & + \\
27 & + & + \\
29 & - & - \\
32 & - & - \\
\hline
\end{tabular}

+, Positive. -, Negative.

macroscopic lesions of goats infected via both routes were observed. The samples of the skin lesions around the muzzle and lips were collected from the time of lesion presentation to recovery, and these samples were used to evaluate of the LAMP method. All experimental procedures and animal care were conducted in accordance with the guidelines and the regulations of the Gansu Animal Care and Use Committee. The experimental protocol was approved by the Ethical Committee of the Lanzhou Veterinary Research Institute, Chinese Academy of Agricultural Sciences (XYXK- (Gan) 2010-003).

\section{DNA extraction}

Briefly, the tissue sample $(25 \mathrm{mg})$ was mechanically homogenized in $250 \mu$ of phosphate-buffered saline (PBS) in a tube using a pellet pestle device. The homogenates were centrifuged at $2000 \times g$ for $3 \mathrm{~min}$, and the supernatant was collected. The DNA templates for the LAMP and RT-PCR assays were extracted using the Universal Genomic DNA Extraction kit (TaKaRa Biotechnology Co., Ltd, Dalian, China) according to the manufacturer's protocol. DNA samples extracted from healthy goats were used in parallel with the experimental samples as negative controls.

\section{LAMP assay}

The LAMP primer sets (Table 2) were designed from the F1L gene region of the published sequence of ORFV isolate Jilin-Nongan (GenBank accession no. JQ271535.1) using

Table 2 Sequence of primers designed for LAMP amplification of the F1L gene of ORFV

\begin{tabular}{lll}
\hline $\begin{array}{l}\text { Primer } \\
\text { name }\end{array}$ & Sequence (5'-3') & $\begin{array}{l}\text { Amplicon size } \\
\text { (F2-B2c) }\end{array}$ \\
\hline F3 & GGTGGTCTACCCCGAGTAC & $782-961^{\text {a }}$ \\
B3 & GGCGATGAACCACAGCAG & \\
FIP (F1C + F2) $)$ & TAGATGGCGCCGGGCCAGA- \\
& AAACGCGGCTCAGCGG & \\
BIP (B1C+B2) & CTCCTTCATGGGGCTCTCGAC- \\
& GCAGCAGCAGCACGAG & \\
\hline
\end{tabular}

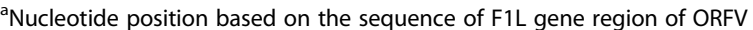
isolate Jilin-Nongan (GenBank accession no. JQ271535.1). 
the Primer Explorer V4 Software (http://primerexplorer.jp/ elamp4.0.0/index.html). The LAMP reaction was carried out as previously described by Thekisoe et al. [24], with minor modifications. The LAMP reaction mixture with a total volume of $25 \mu \mathrm{l}$ contained: $12.5 \mu \mathrm{l}$ of $2 \times$ LAMP reaction buffer $(40 \mathrm{mM}$ Tris- $\mathrm{HCl}$ [pH 8.8], $20 \mathrm{mM} \mathrm{KCl}, 16$ $\mathrm{mM} \mathrm{MgSO}, 20 \mathrm{mM}\left(\mathrm{NH}_{4}\right)_{2} \mathrm{SO}_{4}, 0.2 \%$ Tween $20,1.6 \mathrm{M}$ Betaine, $2.8 \mathrm{mM}$ of each dNTP), $1 \mu \mathrm{l}$ (8 units) of Bst DNA polymerase (New England Biolabs, Massachusetts, USA), $2.6 \mu \mathrm{l}$ primer mix (forward inner primer (FIP) and backward inner primer (BIP) at $40 \mathrm{pmol}$ each, forward outer primer (F3) and forward outer primer (B3) at $10 \mathrm{pmol}$ each), $3 \mu \mathrm{l}$ of template DNA and $5.9 \mu \mathrm{l}$ of double distilled water. LAMP was performed at $63^{\circ} \mathrm{C}$ in a water bath for 1 hour, and samples were identified as positive by agarose gel electrophoresis. LAMP reactions were also stained with SYBR green I dye (TaKaRa Biotechnology Co., Ltd, Dalian, China), and samples were identified as positive by a specific color change when viewed under daylight conditions against a black background.

\section{Sensitivity and specificity of the LAMP assay}

The copy number of the recombinant plasmid containing the F1L gene (PF1L), which was constructed previously by our lab, was calculated as described by Wang et al. [25]. Briefly, the concentration of PF1L (X) was determined by spectrophotometry and converted to number of molecules using the following formula: copies $/ \mathrm{ml}=6.02 \times 10^{23} \times \mathrm{X} / \mathrm{Y}$ $\left(\mathrm{X}=\mathrm{OD}_{260} \times 50 \times 10^{-6} \mathrm{~g} / \mathrm{ml} \times\right.$ dilution factor; $\mathrm{Y}=$ the length of PF1L (bp) $\times 660$ ). The sensitivity of the LAMP assay was then determined using the 10-fold serial dilutions of PF1L. Additionally, the specificity of the LAMP assay was determined using DNA from 10 known isolates of ORFV, 2 strains of capripox virus and 2 strains of FMDV.

\section{Real-time PCR}

The primers for SYBR Green I-based real-time PCR were synthesized according to the published reference [7], 5'CAGCAGAGCCGCGTGAA-3', and 5' -CATGAACCGC TACAACACCTTCT-3'. Real-time PCR was performed with the detection of the B2L gene of ORFV on an $\mathrm{ABI}$ PRISM 7500 thermocycler. The real-time PCR reactions were prepared for a $25 \mu \mathrm{l}$ reaction volume containing $2 \times$ SYBR Premix Ex Taq II supplemented with ROX II, the primers $(10 \mu \mathrm{M}$ each) and $3 \mu \mathrm{l}$ of DNA template. The cycling parameters were as follows: preheat at $95^{\circ} \mathrm{C}$ for $30 \mathrm{~s}$, then 40 cycles of $95^{\circ} \mathrm{C}$ for $5 \mathrm{~s}$ and $64^{\circ} \mathrm{C}$ for $20 \mathrm{~s}$. After amplification, the data were then analyzed using the 7500 System software. A melting curve analysis was performed to verify the uniqueness of the amplified product by its specific melting temperature.

\section{Competing interests}

The authors declare that they have no competing interests.

\section{Authors' contributions}

GXW, YJS and XTL designed the experiment. GXW performed lab work. GXW and YHW participated in data analysis and drafted the manuscript. XTL, YJS and $\mathrm{HT}$ revised the manuscript. All the authors read and approved the final manuscript.

\section{Acknowledgments}

This investigation was financially supported by a grant from the National Modern Meat Caprine Industrial Technology System (nycytx-39). Funding agency had no role in experiment design, data collection, analysis or interpretation, nor in manuscript writing, revision or in manuscript submission.

\section{Author details}

'State Key Laboratory of Veterinary Etiological Biology, Lanzhou 730046, China. ${ }^{2}$ National Foot and Mouth Disease Reference Laboratory, Lanzhou 730046, China. ${ }^{3}$ Key Laboratory of Animal Virology of Ministry of Agriculture, Lanzhou 730046, China. ${ }^{4}$ Lanzhou Veterinary Research Institute, Chinese Academy of Agriculture Science, Lanzhou 730046, China.

Received: 18 October 2012 Accepted: 25 April 2013

Published: 1 May 2013

\section{References}

1. Haig DM, Mercer AA: Ovine Diseases: Orf. Vet Res 1998, 29:311-326.

2. Mondal B, Bera AK, Hosamani M, Tembhurne PA, Bandyopadhyay SK: Detection of orf virus from an outbreak in goats and its genetic relation with other parapoxviruses. Vet Res Commun 2006, 30:531-539.

3. Inoshima Y, Morooka A, Sentsui H: Detection and diagnosis of parapoxvirus by the polymerase chain reaction. J Virol Methods 2000, 84:201-208.

4. Torfason EG, Gunadottir S: Polymerase chain reaction for laboratory diagnosis of orf virus infections. J Clin Virol 2002, 24:79-84.

5. Kottaridi C, Nomikou K, Lelli R, Markoulatos P, Mangana O: Laboratory diagnosis of contagious ecthyma: comparison of different PCR protocols with virus isolation in cell culture. J Virol Methods 2006, 134:119-124.

6. Chan KW, Hsu WL, Wang CY, Yang CH, Lin FY, Chulakasian S, Wong ML: Differential diagnosis of orf viruses by a single-step PCR. J Virol Methods 2009, 160:85-89.

7. Gallina L, Dal Pozzo F, Mclnnes CJ, Cardeti G, Guercio A, Battilani M, Ciulli S, Scagliarini A: A real time PCR assay for the detection and quantification of orf virus. J Virol Methods 2006, 134:140-145

8. Tsai SM, Chana KW, Hsu WL, Chang TJ, Wong ML, Wang CY: Development of a loop-mediated isothermal amplification for rapid detection of orf virus. J Virol Methods 2009, 157:200-204.

9. Li J, Song D, He W, Bao Y, Lu R, Su G, Wang G, Lu H, Zhao K, Gao F: Rapid detection of orf virus by loop-mediated isothermal amplification based on the DNA polymerase gene. Arch Virol. in press.

10. Notomi T, Okayama H, Masubuchi H, Yonekawa T, Watanabe K, Amino N, Hase T: Loop-mediated isothermal amplification of DNA. Nucleic Acids Res 2000, 28:e63.

11. Mori $Y$, Nagamine $K$, Tomita N, Notomi T: Detection of loop-mediated isothermal reaction by turbidity derived from magnesium pyrophosphate formation. Biochem Biophys Res Commun 2001, 289:150-154

12. Tomita N, Mori Y, Kanda H, Notomi T: Loop-mediated isothermal amplification (LAMP) of gene sequences and simple visual detection of products. Nat Protoc 2008, 3:877-882

13. Qiao YM, Guo YC, Zhang XE, Zhou YF, Zhang ZP, Wei HP, Yang RF, Wang DB: Loop-mediated isothermal amplification for rapid detection of Bacillus anthracis spores. Biotechnol Lett 2007, 29:1939-1946.

14. Thekisoe OMM, Bazie RSB, Coronel-Servian AM, Sugimoto C, Kawazu S, Inoue N: Stability of loop-mediated isothermal amplification (LAMP) reagents and its amplification efficiency on crude trypanosome DNA templates. J Vet Med Sci 2009, 71:471-475.

15. Mercer AA, Fleming S, Robinson A, Nettleton P, Reid H: Molecular genetic analysis of parapoxviruses pathogenic for humans. Arch Virol 1997, 13:25-34.

16. Scagliarini A, Ciulli S, Battilani M, Jacoboni I, Montesi F, Casadio R, Prosperi S: Characterisation of immunodominant protein encoded by the $\mathrm{F} 1 \mathrm{~L}$ gene of orf virus strains isolated in Italy. Arch Virol 2002, 147:1989-1995. 
17. Inoshima Y, Murakami K, Wu D, Sentsui H: Characterization of parapoxviruses circulating among wild Japanese serows (Capricornis crispus). Microbiol Immunol 2002, 46:583-587.

18. Hosamani M, Bhanuprakash V, Scagliarini A, Singh RK: Comparative sequence analysis of major envelope protein gene (B2L) of Indian orf viruses isolated from sheep and goats. Vet Microbiol 2006, 116:317-324.

19. Chan KW, Lin JW, Lee SH, Liao CJ, Tsai MC, Hsu WL, Wong ML, Shih HC: Identification and phylogenetic analysis of orf virus from goats in Taiwan. Virus Genes 2007, 35:705-712

20. Abrahão JS, Campos RK, Trindade GS, Guedes MIM, Lobato ZIP, Mazur C, Ferreira PCP, Bonjardim CA, Kroon EG: Detection and phylogenetic analysis of Orf virus from sheep in Brazil: a case report. Virol J 2009, 4:47-50.

21. Jonatas SA, Rafael KC, Giliane ST, Maria IMG, Zelia IPL, Carlos M, Paulo CPF, Claudio $A B$, Erna GK: Detection and phylogenetic analysis of orf virus from sheep in Brazil: acase report. J Virol 2009, 6:47.

22. Zhang KS, Shang YJ, Jin Y, Wang GX, Zheng HX, He JJ, Lu ZX, Liu XT: Diagnosis and phylogenetic analysis of Orf virus from goats in China: a case report. Virol J 2010, 7:78-82.

23. Zhao K, Song D, He W, Lu H, Zhang B, Li C, Chen K, Gao F: Identification and phylogenetic analysis of an orf virus isolated from an outbreak in sheep in the Jilin province of China. Vet Microbiol 2010, 142:408-415.

24. Thekisoe OMM, Rambritch NE, Nakao R, Bazie RS, Mbati P, Namangala B, Malele I, Skilton RA, Jongejan F, Sugimoto C, Kawazu SI, Inoue N: Loopmediated isothermal amplification (LAMP) assays for detection of Theileria parva infections targeting the PIM and p150 genes. Int $J$ Parasitol 2010, 40:55-61.

25. Wang PJ: Development and application of real-time PCR for detection of Toxoplasma gondii, Master's thesis. Chongqing University of Medical Sciences; 2005.

doi:10.1186/1743-422X-10-138

Cite this article as: Wang et al:: Comparison of a loop-mediated isothermal amplification for orf virus with quantitative real-time PCR. Virology Journal 2013 10:138.

\section{Submit your next manuscript to BioMed Central and take full advantage of:}

- Convenient online submission

- Thorough peer review

- No space constraints or color figure charges

- Immediate publication on acceptance

- Inclusion in PubMed, CAS, Scopus and Google Scholar

- Research which is freely available for redistribution 